Grace A. Ashley • Junaid Shabbeer • Makiko Yasuda

Christine M. Eng • Robert J. Desnick

\title{
Fabry disease: twenty novel $\alpha$-galactosidase A mutations causing the classical phenotype
}

Received: November 17, 2000 / Accepted: January 9, 2001

\begin{abstract}
Fabry disease, an X-linked inborn error of glycosphingolipid catabolism, results from the deficient activity of the lysosomal exoglycohydrolase, $\alpha$-galactosidase A (EC 3.2.1.22; $\alpha$-Gal A). The nature of the molecular lesions in the $\alpha$-Gal $A$ gene in 40 unrelated families with the classical phenotype (absent $\alpha$-Gal A activity) was determined in order to provide precise heterozygote detection and prenatal diagnosis, and to explore possible genotype/ phenotype correlations. Genomic DNA was isolated from unrelated affected males, and the entire $\alpha$-Gal $A$ coding region and flanking intronic sequences were analyzed by polymerase chain reaction (PCR) amplification and automated sequencing. Twenty new mutations were identified: M51K, D92N, D136H, F169S, C172F, L191Q, S247P, Q250X, P259R, G261D, T282N, R301P, W349X, T410K, 124delAT, 842delTAA, 1033delTC, 82insG, 893insG, and 903insG. In the remaining 20 unrelated Fabry families, 17 previously reported mutations were detected. These studies further define the heterogeneity of mutations in the $\alpha-G a l$ $A$ gene causing the classic Fabry disease phenotype, and permit precise heterozygote detection and prenatal diagnosis.
\end{abstract}

Key words Fabry disease - Lysosomal storage disease · Mutation analysis $\cdot \alpha$-galactosidase $\mathrm{A} \cdot$ Genetic heterogeneity

G.A. Ashley $\cdot$ J. Shabbeer $\cdot$ M. Yasuda $\cdot$ C.M. Eng

R.J. Desnick $(\varangle)$

Department of Human Genetics, Mount Sinai School of Medicine,

Fifth Avenue at 100th Street, New York, NY 10029, USA

Tel. +1-212-659-6700; Fax: +1-212-360-1809

e-mail: rjdesnick@mssm.edu

M. Yasuda

Department of Pediatrics, Tokyo Womens' Medical University,

Tokyo, Japan

The first two authors contributed equally to this work.

\section{Introduction}

Fabry disease is an X-linked inborn error of glycosphingolipid catabolism resulting from the deficient activity of the lysosomal exoglycohydrolase, $\alpha$-galactosidase A (EC 3.2.1.22; $\alpha$-Gal A) (Desnick et al. 2000.) Affected individuals accumulate neutral glycosphingolipids with terminal $\alpha$ linked galactosyl moieties in the plasma and in lysosomes throughout the body. In classically affected males, who have little, if any, $\alpha-$ Gal A activity, the onset of the disease manifestations occurs in childhood or adolescence, and is characterized by severe acroparesthesias, angiokeratoma, corneal opacities, and hypohidrosis. With advancing age, vascular disease of the heart, kidneys, and brain leads to early demise, typically in the fourth and fifth decades of life. Currently, there is no specific treatment for Fabry disease, but recent animal and human clinical trials have indicated the feasibility of recombinant enzyme replacement therapy (Ioannou et al. 2001; Eng et al. 2000, 2001).

The isolation and sequencing of the full-length cDNA and entire 12-kb genomic sequence encoding $\alpha$-Gal $A$ (Bishop et al. 1986; Kornreich et al. 1989) has facilitated characterization of the mutations causing Fabry disease. To date, a variety of mutations have been identified, including missense, nonsense, and splice-site mutations, as well as partial gene rearrangements, small deletions, and insertions, e.g., by Eng and Desnick (1994); Eng et al. (1994); and Eng et al. (1997) (see also the Human Gene Mutation Database http:// archive. uwcm. ac. uk/ uwcm/ mg/ hgmd0. html). Most mutations have been private (unique to each family), with the exception of a few common mutations, found in several unrelated individuals, involving $\mathrm{CpG}$ dinucleotides, known hotspots for mutation (Barker et al. 1984; Cooper and Youssoufian, 1988; Eng et al. 1994).

Although the diagnosis of Fabry disease in affected males can be made reliably by demonstrating markedly deficient $\alpha$-Gal A activity in plasma, leukocytes, or cultured cells (Desnick et al. 1973), the enzymatic identification of heterozygous females is less reliable because of random $\mathrm{X}$ chromosome inactivation (Lyon 1961; Brown and Brown 
1993; Desnick et al. 2000). In fact, the finding of normal $\alpha$ Gal A activity in an at-risk female does not exclude heterozygosity (Avila et al. 1973; Ashton-Prolla et al. 2000). Only the presence of an $\alpha$-Gal $A$ mutation in an at-risk female will provide precise carrier identification. Thus, mutation and/or haplotype analyses (Caggana et al. 1997), are required not only for carrier identification, but also for precise prenatal diagnosis, genotype/phenotype relationships, and future structure/function studies.

In this communication, mutation analysis of the $\alpha$-Gal $A$ gene was performed in 40 unrelated families with Fabry disease. Twenty novel mutations were identified in 20 of these families, while in the remaining 20 families, 17 previously reported mutations were detected.

\section{Methods}

Patient specimens

Peripheral blood was collected, in ethylenediaminetetraacetic acid (EDTA) from 40 unrelated classically affected males with enzymatically diagnosed Fabry disease. In each family, the classic Fabry phenotype was confirmed after evaluation of the family history and disease manifestations in the probands by the authors (R.J.D. and/or C.M.E.). Genomic DNA was extracted using the Puregene isolation kit according to the manufacturer's conditions (Gentra Systems, Minneapolis, MN, USA). Lymphoblast cell lines were established and maintained according to the methods of Anderson and Gusella (1984). All specimens were obtained with informed consent and with the approval of the Institutional Review Board of the Mount Sinai School of Medicine.

\section{Mutation analysis}

Mutation analysis was performed by multiplex amplification of the $\alpha$-Gal $A$ exons and adjacent flanking and intronic DNA sequences from genomic DNA (Kornreich and
Desnick 1993). PCR primers were designed with a GC-rich tag (Table 1), allowing the simultaneous amplification of all seven exons in four discrete products. Each amplicon was sequenced using an ABI Prism 377 Automated DNA Sequencer using the ABI Prism BigDye Terminator Ready Reaction mix (Perkin-Elmer-Cetus Norwalk, CT, USA). Each mutation was confirmed by repeat PCR-amplification and sequencing of the opposite strand, and/or by cosegregation of the lesion and disease phenotype in each family.

\section{Results}

The $\alpha$-Gal $A$ mutations causing Fabry disease in 40 unrelated probands were determined by multiplex PCR amplification and automated sequencing of the entire coding sequence and adjacent intronic regions. No large $\alpha$-Gal $A$ rearrangements (more than $50 \mathrm{bp}$ ) were observed in any of the probands following electrophoresis of the PCR products. Sequencing revealed 20 novel mutations, each a private family mutation, including 14 missense or nonsense mutations, three small deletions, and three small insertions. In addition, 17 previously published mutations were identified in 20 families, including ten missense mutations (M1T, A143T, G144V, C172Y, N215S, I289F, N298K, R301Q, R342Q, and G361R) (Sakuraba et al. 1990; Davies et al. 1993; Ploos van Amstel et al. 1994; Eng et al. 1994; Davies et al. 1996; Blanch et al. 1996; Eng et al. 1997; Topaloglu et al. 1999), six nonsense mutations (Q119X, W162X, R220X [two families], R227X [three families], R301X, and R342X) (Meaney et al. 1994; Eng et al. 1994; Davies et al. 1996; Rosenberg et al. 1999), and one single-base deletion (777del1) (Eng et al. 1997). In each proband, the sequencing of the entire coding and adjacent flanking intronic regions revealed a single lesion in each mutant allele. Tables 2 and 3 summarize the 20 novel and 17 recurrent mutations that were identified in affected males with the classic phenotype.

Of the 14 novel $\alpha$-Gal $A$ coding-region point mutations, 12 were missense and two were nonsense mutations. The

Table 1. Primers used for PCR and sequencing

All PCR primers had the following 20 nucleotide sequence at the $5^{\prime}$ end (Shuber et al. 1995):

GCGGTCCCAAAAGGGTCAGT

PCR primers

Exon 1

Exon 2

Exons 3-4

Exons 5-7

Sequencing primers

Exon 1

Exon 2

Exon 3

Exon 4

Exon 5

Exon 6

Exon 7
5'-GGATCACTAAGGTGCCGC-3'

5'-CTTGTGATTACTACCACACT-3'

5'-TAGCTCAGCAGAACTGGGGGATTT-3'

5'-GTTTAGACCTCCTTATGGAGA-3'

5'-TGATTGGTCCGCCCCTG-3'

5'-TGCCTAATAAATGGGAG-3'

5'-TGGTTCTCTCTTTCTGCTACC-3'

5'-TATAGCCCCAGCTGGAAATT-3'

5'-TATTTACCTTGAATGTC-3'

5'-GGGTCATCTAGGTAACTTTAAG-3'

5'-ATGAATGCCAAACTAAC-3'
5'-AACTGTTCCCGTTGA-3'

5'-ACAAGCTTCTGTACAGAAGTGC3'

5'-GTAAGTAACGTTGGACT-3'

5'-CAGGAAGTAGTAGTTGG-3'

5'-TCCCCAAACACACCCAAA-3'

5'-AGAAGTGCTTACAGTCC-3'

5'-TTGTGGCTAAATCTCTGG-3'

5'-GTAAGTAACGTTGGACT-3'

5'-CTTACAAGGATGTTAGT-3'

5'-AGATTTAGGCCCAAGAC-3'

5'-CAGGAAGTAGTAGTTGG-3'

PCR, Polymerase chain reaction 
Table 2. Novel mutations

\begin{tabular}{|c|c|c|c|c|}
\hline Location & $\begin{array}{l}\text { Genomic } \\
\text { nucleotide change }\end{array}$ & $\begin{array}{l}\text { cDNA nucleotide } \\
\text { change }\end{array}$ & Mutation & Phenotype \\
\hline \multicolumn{5}{|c|}{ Missense mutations } \\
\hline Exon 1 & $\mathrm{~g} 1331 \mathrm{~T} \rightarrow \mathrm{A}$ & $152 \mathrm{ATG} \rightarrow \mathrm{AAG}$ & M51K & Classic \\
\hline Exon 2 & g5176G $\rightarrow$ A & $274 \mathrm{GAT} \rightarrow \mathrm{AAT}$ & D92N & \\
\hline Exon 3 & g7305 G $\rightarrow C$ & $406 \mathrm{GAT} \rightarrow \mathrm{CAT}$ & $\mathrm{D} 136 \mathrm{H}$ & Classic \\
\hline Exon 3 & $\mathrm{~g} 7405 \mathrm{~T} \rightarrow \mathrm{C}$ & $506 \mathrm{TTT} \rightarrow$ TCT & F169S & \\
\hline Exon 3 & $\mathrm{~g} 7414 \mathrm{G} \rightarrow \mathrm{T}$ & $515 \mathrm{TGT} \rightarrow \mathrm{TTT}$ & $\mathrm{C} 172 \mathrm{~F}$ & Classic \\
\hline Exon 4 & $\mathrm{~g} 8345 \mathrm{~T} \rightarrow \mathrm{A}$ & $572 \mathrm{CTG} \rightarrow \mathrm{CAG}$ & L191Q & \\
\hline Exon 5 & $\mathrm{~g} 10230 \mathrm{~T} \rightarrow \mathrm{C}$ & $739 \mathrm{TCT} \rightarrow \mathrm{CCT}$ & S247P & \\
\hline Exon 5 & $\mathrm{~g} 10267 \mathrm{C} \rightarrow \mathrm{G}$ & $776 \mathrm{CCA} \rightarrow \mathrm{CGA}$ & P259R & \\
\hline Exon 5 & $\mathrm{~g} 10273 \mathrm{G} \rightarrow \mathrm{A}$ & $782 \mathrm{GGT} \rightarrow \mathrm{GAT}$ & G261D & Classic \\
\hline Exon 6 & $\mathrm{~g} 10553 \mathrm{C} \rightarrow \mathrm{A}$ & $845 \mathrm{ACT} \rightarrow \mathrm{AAT}$ & $\mathrm{T} 282 \mathrm{~N}$ & Classic \\
\hline Exon 6 & $\mathrm{~g} 10610 \mathrm{G} \rightarrow \mathrm{C}$ & $902 \mathrm{CGA} \rightarrow \mathrm{CCA}$ & $\mathrm{R} 301 \mathrm{P}$ & Classic \\
\hline Exon 7 & $\mathrm{~g} 11207 \mathrm{C} \rightarrow \mathrm{A}$ & $1229 \mathrm{ACA} \rightarrow \mathrm{AAA}$ & $\mathrm{T} 410 \mathrm{~K}$ & \\
\hline \multicolumn{5}{|c|}{ Nonsense mutations } \\
\hline Exon 5 & $\mathrm{~g} 10239 \mathrm{C} \rightarrow \mathrm{T}$ & $748 \mathrm{CAG} \rightarrow \mathrm{TAG}$ & Q250X & Classic \\
\hline Exon 7 & $\mathrm{~g} 11024 \mathrm{G} \rightarrow \mathrm{A}$ & $1046 \mathrm{TGG} \rightarrow \mathrm{TAG}$ & W349X & Classic \\
\hline \multicolumn{5}{|c|}{ Small deletions } \\
\hline Exon 1 & g1303delAT & 124delAT & $\mathrm{ACC} a t \mathrm{G}$ GGC & Classic \\
\hline Exon 6 & g10550delTAA & 842delTAA & CAA Gta $a \mathrm{CT}$ & Classic \\
\hline Exon 7 & g11011delTC & 1033delTC & CTC $t c$ A GGC & Classic \\
\hline \multicolumn{5}{|c|}{ Small insertions } \\
\hline Exon 1 & g1260insG & 82insG & ATC CCT gGG GG & Classic \\
\hline Exon 6 & g10601insG & 893insG & TCT AAg TGA C & \\
\hline Exon 6 & g10611insG & 903insG & CTC CGg ACA C & Classic \\
\hline
\end{tabular}

Table 3. Previously reported mutations

\begin{tabular}{|c|c|c|c|c|}
\hline Location & $\begin{array}{l}\text { Genomic } \\
\text { nucleotide change }\end{array}$ & $\begin{array}{l}\text { cDNA } \\
\text { nucleotide change }\end{array}$ & Mutation & Reference \\
\hline \multicolumn{5}{|c|}{ Missense mutations } \\
\hline Exon 1 & $\mathrm{~g} 1181 \mathrm{~T} \rightarrow \mathrm{C}$ & $2 \mathrm{ATG} \rightarrow \mathrm{ACG}$ & M1T & Eng et al. (1997) \\
\hline Exon 3 & $\mathrm{~g} 7326 \mathrm{G} \rightarrow \mathrm{A}$ & $427 \mathrm{GCA} \rightarrow \mathrm{ACA}$ & A143T & Eng et al. (1997) \\
\hline Exon 3 & g7330 G $\rightarrow$ T & $431 \mathrm{GGC} \rightarrow \mathrm{GTC}$ & G144V & Eng et al. (1994) \\
\hline Exon 3 & g7414 G $\rightarrow$ A & $515 \mathrm{TGT} \rightarrow \mathrm{TAT}$ & $\mathrm{C} 172 \mathrm{Y}$ & Eng et al. (1994) \\
\hline Exon 5 & $\mathrm{~g} 10135 \mathrm{~A} \rightarrow \mathrm{G}$ & $644 \mathrm{AAT} \rightarrow \mathrm{AGT}$ & $\mathrm{N} 215 \mathrm{~S}$ & Davies et al. (1993) \\
\hline Exon 6 & $\mathrm{~g} 10573 \mathrm{~A} \rightarrow \mathrm{T}$ & $864 \mathrm{ATC} \rightarrow \mathrm{TTC}$ & $\mathrm{I} 289 \mathrm{~F}$ & Topaloglu et al. (1999) \\
\hline Exon 6 & $\mathrm{G} 10602 \mathrm{~T} \rightarrow \mathrm{G}$ & $894 \mathrm{AAT} \rightarrow \mathrm{AAG}$ & N298K & Blanch et al. (1996) \\
\hline Exon 6 & $\mathrm{~g} 10610 \mathrm{G} \rightarrow \mathrm{A}$ & $902 \mathrm{CGA} \rightarrow \mathrm{CAA}$ & R301Q & Sakuraba et al. (1990) \\
\hline Exon 7 & $\mathrm{~g} 10536 \mathrm{G} \rightarrow \mathrm{A}$ & $1025 \mathrm{CGA} \rightarrow \mathrm{CAA}$ & $\mathrm{R} 342 \mathrm{Q}$ & Ploos van Amstel et al. (1994) \\
\hline Exon 7 & $\mathrm{~g} 11059 \mathrm{G} \rightarrow \mathrm{A}$ & $1081 \mathrm{GGA} \rightarrow \mathrm{AGA}$ & G361R & Davies et al. (1993) \\
\hline \multicolumn{5}{|c|}{ Nonsense mutations } \\
\hline Exon 2 & g5254 C $\rightarrow T$ & $355 \mathrm{CAG} \rightarrow \mathrm{TAG}$ & Q119X & Davies et al. (1996) \\
\hline Exon 3 & $\mathrm{~g} 7385 \mathrm{G} \rightarrow \mathrm{A}$ & $485 \mathrm{TGG} \rightarrow \mathrm{TAG}$ & W162X & Rosenberg et al. (1999) \\
\hline Exon 5 & g10149 C $\rightarrow$ T CpG & $658 \mathrm{CGA} \rightarrow \mathrm{TGA}$ & $\mathrm{R} 220 \mathrm{X}$ & Meaney et al. (1994) \\
\hline Exon 5 & $\mathrm{~g} 10170 \mathrm{C} \rightarrow \mathrm{T} \mathrm{CpG}$ & $679 \mathrm{CGA} \rightarrow \mathrm{TGA}$ & $\mathrm{R} 227 \mathrm{X}$ & $\begin{array}{l}\text { Davies et al. (1993) } \\
\text { Eng et al. (1993) }\end{array}$ \\
\hline Exon 6 & $\mathrm{~g} 10609 \mathrm{C} \rightarrow \mathrm{T}$ & $901 \mathrm{CGA} \rightarrow \mathrm{TGA}$ & R301X & Eng et al. (1994) \\
\hline Exon 7 & $\mathrm{~g} 11002 \mathrm{C} \rightarrow \mathrm{T}$ & $1024 \mathrm{CGA} \rightarrow \mathrm{TGA}$ & $\mathrm{R} 342 \mathrm{X}$ & Davies et al. (1996) \\
\hline \multicolumn{5}{|c|}{ Small deletions } \\
\hline Exon 5 & g10268delA & 777 delA & GGA CCa GGG & Eng et al. (1997) \\
\hline
\end{tabular}

missense mutations included: (1) a T-to-A transversion of genomic nucleotide g1331 in codon 51 of exon 1, resulting in the replacement of a neutral, polar methionine for a basic lysine residue $(\mathrm{M} 51 \mathrm{~K})$. The normal methionine is conserved only in the mammalian orthologues, monkey, mouse, and hamster; (2) a G-to-A transition of genomic nucleotide g5176 in codon 92 of exon 2, resulting in the substitution of a neutral nonpolar asparagine for aspartic acid (D92N). The normal aspartate is highly conserved in the three mammalian orthologues, in all 14 other eukaryotic and five of the six prokaryotic orthologues, and in all four sequences encoding the related enzyme, $\alpha$-galactosidase B ( $\alpha$-Gal B; i.e., human, mouse, chicken, and Caenorhabditis elegans); (3) a G-to-C transversion of genomic nucleotide g7305 in codon 136 of exon 3, resulting in the substitution of a basic histidine residue for aspartic acid (D136H). The normal aspartate is conserved in the three mammalian orthologues, in 4 of 14 other eukaryotic and one of six prokaryotic orthologues, and in all four $\alpha$-Gal $B$ sequences; (4) a T-to-C transition of genomic nucleotide g7405 in codon 169 
of exon 3, resulting in the replacement of a hydrophilic phenylalanine for a hydrophobic serine residue (F169S). The phenylalanine is conserved in monkey, mouse, and hamster $\alpha$-Gal $A$; (5) a G-to-T transversion of genomic nucleotide g7414 in codon 172 of exon 3, substituting a hydrophilic phenylalanine for a hydrophobic cysteine residue $(\mathrm{C} 172 \mathrm{~F})$. The cysteine is very highly conserved in all 18 eukaryotic and one of six prokaryotic orthologues, and in all four $\alpha$-Gal B sequences; (6) a T-to-A transversion of genomic nucleotide 8345 in codon 191 of exon 4, resulting in the change of a hydrophilic leucine to a hydrophobic glutamine residue (L191Q). The leucine is very highly conserved conserved in all 18 eukaryotic and one of six prokaryotic orthologues, and in all four $\alpha$-Gal B sequences; (7) a T-to-C transition of genomic nucleotide g10230 in codon 247 of exon 5, predicting the substitution of a hydrophilic proline for hydrophobic serine residue (S247P). The serine residue is conserved only in monkey $\alpha$ Gal A; (8) a C-to-G transversion of genomic nucleotide 10267 in codon 259 of exon 5, resulting in the replacement of a neutral, polar proline residue by the basic amino acid arginine (P259R). The proline was conserved in 8 of 18 eukaryotic and three of six prokaryotic orthologues, and in all four $\alpha$-Gal B sequences; (9) a G-to-A transition of genomic nucleotide g10273 in codon 261 of exon 5, resulting in the replacement of an aspartic acid for a neutral, polar glycine residue (G261D). The glycine is highly conserved in 15 of 18 eukaryotic and one of six prokaryotic orthologues, but not in any of the four $\alpha$-Gal B sequences; (10) a C-to-A transversion of genomic nucleotide g10553 in codon 282 of exon 6 , predicting a threonine-to-asparagine change. The threonine is conserved in only 6 of 18 eukaryotic orthologues; (11) a G-to-C transversion of genomic nucleotide g10610 in codon 301 of exon 6, predicting the replacement of a basic arginine residue for the neutral, polar amino acid proline (R301P). The arginine is conserved in 7 of 18 eukaryotic and four of six prokaryotic orthologues, and in all four $\alpha$-Gal B sequences; and (12) a C-to-A transversion of genomic nucleotide g11207 in codon 410 of exon 7, predicting the substitution of a basic lysine for a neutral, nonpolar threonine residue (T410K). The threonine is conserved only in monkey $\alpha$-Gal $A$. The two novel nonsense mutations included a C-to-T transition of genomic nucleotide g10239 in codon 250 of exon 5, predicting a glutamine to termination codon (Q250X), deleting 180 amino acids, and a G-to-A transition of genomic nucleotide g11024 in codon 349 of exon 7, resulting in a tryptophan to termination codon (W349X), and deleting 81 residues.

Six novel small gene rearrangements, including three small deletions and three small insertions, were identified in unrelated classically affected probands. Of the three small deletions, two caused frameshift mutations, one occurring in exon 1 and one in exon 7. These included: (1) a two-base deletion (124delAT) of genomic nucleotides g1303 and g1304, predicting a frameshift at codon 42 , altering residues 42 to 53 then causing a premature termination at codon 54 ; (2) a two-base deletion (1033delTC) of genomic nucleotides g11011-11012 that caused a frameshift at codon 345, altering residues 345 to 372 and prematurely terminating the polypeptide at residue 373 ; (3) a three-base out-of-phase deletion (842delTAA) of genomic nucleotides g10550g10552 that occurred in exon 6 and resulted in a valine-toalanine change at codon 281 , altering the protein sequence from residues 281 to 427 with premature protein truncation at residue 428. In addition, the three small insertions (one in exon 1 and two in exon 6) all involved the insertion of a guanine residue. These included: (1) 82insG, occurring after genomic nucleotide g1260 in exon 1, resulting in an alanineto-glycine substitution at codon 29 of exon 1 . This introduced a termination signal at codon 30 , the penultimate codon in the leader sequence; (2) 893insG, occurring after genomic nucleotide g10601 in exon 6, predicting an asparagine-to-lysine change at codon 298 , and predicting termination of the polypeptide chain at codon 299; and (3) 903 ins G, causing a frameshift after genomic nucleotide g10611 in exon 6, which predicted the incorporation of a serine-rich segment of 12 different amino acids (THQPSSQSSPSG) and premature termination of the polypeptide at codon 314.

\section{Discussion}

Sequencing the $\alpha$-Gal $A$ gene in genomic DNA from 40 unrelated probands with Fabry disease revealed 20 novel and 17 previously reported mutations. Each of the 20 novel mutations was identified in unrelated families among the 40 families studied, demonstrating the extensive molecular heterogeneity in this disease. The novel mutations were dispersed along the gene, and included 14 missense or nonsense point mutations, and six small insertions or deletions in the coding region. Of the novel mutations, one was of particular interest. The insertion, g82insG, caused a frameshift in codon 30 . This would terminate the polypeptide in the leader sequence, so no mature polypeptide would be synthesized. Presumably, the 29-amino acid polypepetide would remain in the endoplasmic reticulum and then would be degraded in the proteasomes. Only one novel mutation (R301P) occurred at a $\mathrm{CpG}$ dinucleotide, whereas 6 (R220X, R227X, R301Q, R301X, R342Q, and R342X) of the 17 previously reported mutations occurred at $\mathrm{CpG}$ dinucleotides, known hotspots for mutation (Eng et al. 1994; Desnick et al. 2000).

Of the six gene rearrangements, three occurred in exon 6 (g842delTAA, g893insG, and g903insG) and one occurred in exon 7 (g1033delTC). The identification of these small deletions and insertions supports the previous suggestion that exon 7 is a region prone to small gene rearrangements (Eng et al. 1997), and also implicates exon 6 as being similarly prone to these small insertions and deletions.

In summary, the identification of these 20 new mutations further demonstrates the genetic heterogeneity of the $\alpha-G a l$ $A$ lesions causing Fabry disease. Mutation analysis is important for each Fabry family, because detection of these mutations allows the precise diagnosis of heterozygous carriers of the X-linked recessive gene, and provides the ability to perform precise prenatal diagnoses. In addition, the detec- 
tion of these new mutations is useful for the evaluation of genotype-phenotype correlations, and provides an insight into the enzyme's structure-function relationships.

Acknowledgments This work was supported in part by grants from the National Institutes of Health, including a Merit Award (5 R37 DK34045), a grant (5 M01 RR00071) for the Mount Sinai General Clinical Research Center, and a grant (5 P30 HD28822) for the Mount Sinai Child Health Research Center.

\section{References}

Anderson MA Gusella JF (1984) Use of cyclosporin A in establishing Epstein-Barr virus-transformed human lymphoblastoid cell lines. In vitro 20:856-858

Ashton-Prolla P, Tong B, Shabbeer J, Astrin KH, Eng CM, Desnick RJ (2000) Fabry disease: 22 novel mutations in the alpha-galactosidase A gene and genotype/phenotype correlations in severely and mildly affected hemizygotes and heterozygotes. J Invest Med 48:227235

Avila JL, Convit J, Velazquez-Avila G (1973) Fabry's disease: normal alpha-galactosidase activity and urinary-sediment glycosphingolipid levels in two obligate heterozygotes. Br J Dermatol 89:149-157

Barker D, Schafer M, White R (1984) Restriction sites containing CpG show a higher frequency of polymorphism in human DNA. Cell 36:131-138

Bishop DF, Calhoun DH, Bernstein HS, Hantzopoulos P, Quinn M, Desnick RJ (1986) Human alpha-galactosidase A: nucleotide sequence of a cDNA clone encoding the mature enzyme. Proc Natl Acad Sci USA 83:4859-4863

Blanch LC, Meaney C, Morris CP (1996) A sensitive mutation screening strategy for Fabry disease: detection of nine mutations in the $\alpha$ galactosidase A gene. Hum Mut 8:38-43

Brown RM, Brown GK(1993) X chromosome inactivation and the diagnosis of X-linked disease in females. J Med Genet 30:177-184

Caggana M, Ashley GA, Desnick RJ, Eng CM (1997) Molecular carrier detection and prenatal diagnosis by analysis of closely linked polymorphisms at Xq22.1. Am J Med Genet 71:329-335

Cooper DN, Youssoufian H (1988) The CpG dinucleotide and human genetic disease. Hum Genet 78:151-155

Davies JP, Winchester BG, Malcolm S (1993) Mutation analysis in patients with the typical form of Anderson-Fabry disease. Hum Mol Genet 2:1051-1053

Davies JP, Eng CM, Hill JA, Malcolm S, MacDermot K, Winchester B, Desnick RJ (1996) Fabry disease: 14 alpha-galactosidase A mutations in unrelated families from the United Kingdom and other European countries. Eur J Hum Genet 4:219-224

Desnick RJ, Allen KY, Desnick SJ, Raman MK, Bernlohr RW, Krivit W (1973) Fabry disease: enzymatic diagnosis of hemizgotes and heterozygotes. $\propto$-Galactosidase activities in plasma, serum, urine and leukocytes. J Lab Clin Med 81:157-171

Desnick RJ, Ioannou YA, Eng CM (2000) Fabry disease. In: Scriver CR, Beaudet AL, Sly WS, Valle D, Kinzler KE, Vogelstein (eds)
The metabolic and molecular base of inherited disease. McGrawHill, New York pp. 3733-3774

Eng CM, Desnick RJ (1994) Molecular basis of Fabry disease: mutations and polymorphisms in the human alpha-galactosidase A gene. Hum Mutat 3:103-111

Eng CM, Resnick-Silverman LA, Niehaus DJ, Astrin KH, Desnick RJ (1993) Nature and frequency of mutations in the $\alpha$-galactosidase A gene that cause Fabry disease. Am J Hum Genet 53:1186-1197

Eng CM, Niehaus DJ, Enriquez AL, Burgert TS, Ludman MD, Desnick RJ (1994) Fabry disease: 23 mutations including sense and antisense $\mathrm{CpG}$ alterations and identification of a deletional hotspot in the alpha-galactosidase A gene. Hum Mol Genet 3:1795-1799

Eng CM, Ashley GA, Burgert TS, Enriquez AL, D'Souza M, Desnick RJ (1997) Fabry disease: 35 mutations in the alpha-galactosidase A gene in patients with classic and variant phenotypes. Mol Med 3:174182

Eng CM, Cochat P, Wilcox WR, Germain DP, Lee P, Waldek S, Caplan L, Heymans H, Braakman T, Fitzpatrick MA, Huertas P, O'Callaghan MW, Richards S, Tandon PK, Desnick R (2000) Enzyme replacement therapy in Fabry disease: results of a placebocontrolled phase 3 trial. Am J Hum Genet 67:A134

Eng CM, Banikazemi M, Gordon R, Goldman M, Phelps R, Kim L, Gass A, Winston J, Dickman S, Stacy CB, Fallon JT, Brodie S, Mehta D, Parsons R, Norton K, O'Callaghan M, Desnick RJ (2001) A phase $1 / 2$ clinical trial of enzyme replacement in Fabry disease: pharmacokinetic, substrate clearance, and safety studies. Am J Hum Genet 68

Ioannou YA, Zeidner KM, Gordon RE, Desnick RJ (2001) Fabry disease: preclinical studies demonstrate the effectiveness of $\alpha$-galactosidase A replacement in enzyme-deficient mice. Am J Hum Genet 68:14-25

Kornreich R, Bishop DF, Desnick RJ (1989) The gene encoding alphagalactosidase $\mathrm{A}$ and gene rearrangements causing Fabry disease. Trans Assoc Am Physicians 102:30-43

Kornreich R, Desnick RJ (1993) Fabry disease: detection of gene rearrangements in the human alpha-galactosidase A gene by multiplex PCR amplification. Hum Mutat 2:108-111

Lyon MF (1961) Gene action in the X-chromosome of the mouse. Nature 190:372-373

Meaney C, Blanch LC, Morris CP (1994) A nonsense mutation $(\mathrm{R} 220 \mathrm{X})$ in the alpha-galactosidase A gene detected in a female carrier of Fabry disease. Hum Mol Genet 3:1019-1020

Ploos van Amstel JK, Jansen RP, de Jong JG, Hamel BC, Wevers RA (1994) Six novel mutations in the alpha-galactosidase A gene in families with Fabry disease. Hum Mol Genet 3:503-505

Rosenberg KM, Schiffmann R, Kaneski C, Brady RO, Sorensen SA, Hasholt L (1999) Five novel mutations in 14 patients with Fabry disease. Hum Mut Mutations in Brief Online \#292

Sakuraba H, Oshima A, Fukuhara Y, Shimmoto M, Nagao Y, Bishop DF, Desnick RJ, Suzuki Y (1990) Identification of point mutations in the alpha-galactosidase A gene in classical and atypical hemizygotes with Fabry disease. Am J Hum Genet 47:784-789

Shuber AP, Grondin VJ, Klinger KW (1995) A simplified procedure for developing multiplex PCRs. Genet Res 5:488-493

Topaloglu AK, Ashley GA, Tong B, Shabbeer J, Astrin KH, Eng CM, Desnick RJ (1999) Twenty novel mutations in the alphagalactosidase A gene causing Fabry disease. Mol Med 5:806-811 